\title{
Optimasi Biaya Perawatan Sistem dengan Faktor Diskon
}

\author{
Desyandi Ayuriza, Suyono, dan Fariani Hermin \\ Jurusan Matematika FMIPA UNJ
}

\begin{abstract}
Abstrak
Kegiatan perawatan dapat meminimalkan biaya atau kerugian yang ditimbulkan, apabila terdapat kerusakan pada suatu sistem. Biaya total perawatan bergantung pada jumlah dari tindakan perawatan preventif dan korektif yang dilakukan selama interval waktu tertentu. Skripsi ini membahas biaya total perawatan sistem dari komponen dalam waktu yang terbatas. Strategi penggantian usia komponen diasumsikan sebagai kerusakan komponen yang mengikuti sebuah proses gamma. Asumsikan faktor diskon yang perlu dimasukkan ke dalam perhitungan untuk mempersiapkan biaya yang diperlukan untuk biaya perawatan komponen pada interval waktu [0,t], maka akan menghasilkan waktu yang optimal antara perawatan preventif yang dilakukan secara berurutan untuk meminimalkan nilai ekspektasi dari biaya total perawatan. Sebuah contoh numerik dibahas pada bagian akhir skripsi ini untuk mengilustrasikan hasil yang telah diperoleh.
\end{abstract}

Kata kunci: strategi penggantian usia, proses Gamma, pendiskonan, proses Renewal, transformasi Laplace.

\section{Pendahuluan}

\section{A. Latar Belakang}

Dalam kehidupan sehari-hari banyak dijumpai sesuatu yang dapat dipandang sebagai sebuah sistem. Sebagai contoh, mobil adalah sebuah sistem yang terdiri dari beberapa komponen. Komponen dalam suatu sistem tidak dapat berdiri sendiri. Komponen-komponen tersebut saling berinteraksi dan saling berhubungan membentuk suatu kesatuan, sehingga tujuan atau sasaran dapat tercapai. Sistem biasanya bekerja untuk keperluan tertentu. Sebagai contoh, mobil yang bekerja sebagai alat transportasi. Mesin produksi yang bekerja pada mobil berguna untuk menghasilkan energi-energi tertentu, sehingga mobil tersebut dapat berjalan. Agar sistem dapat bekerja dengan baik (sesuai yang diharapkan), maka sistem memerlukan perawatan.

Kegiatan perawatan mempunyai peranan yang sangat penting karena sebagai pendukung suatu sistem agar berjalan lancar sesuai yang diharapkan. Selain itu, kegiatan perawatan juga dapat meminimalkan biaya atau kerugian yang ditimbulkan, apabila terdapat kerusakan pada suatu sistem. Perawatan dapat dibagi menjadi beberapa kategori, tergantung dari dasar yang dipakai untuk menggolongkannya. Tetapi, pada dasarnya, terdapat dua kegiatan pokok dalam perawatan, yaitu perawatan preventif dan perawatan korektif. Perawatan preventif merupakan suatu kegiatan untuk menjaga keadaan sistem, sebelum sistem tersebut mengalami kerusakan, sedangkan perawatan korektif merupakan suatu kegiatan untuk memperbaiki sistem yang telah mengalami kerusakan.

Pada umumnya, biaya untuk perawatan preventif lebih kecil daripada biaya untuk perawatan korektif. Dalam interval waktu tertentu, biaya perawatan total bergantung pada jumlah dari tindakan perawatan preventif dan korektif yang dilakukan selama interval waktu tersebut. Biaya perawatan total dapat sangat besar jika perawatan preventif yang terlalu sering atau terlalu jarang, sehingga akan meningkatkan biaya perawatan korektif total. Dari penjelasan tersebut menimbulkan sebuah pertanyaan menarik, yaitu seberapa sering perawatan preventif harus dilakukan untuk meminimalkan biaya perawatan total selama interval waktu tertentu.

Beberapa penulis sebelumnya telah membahas biaya perawatan total. Ekspektasi biaya ratarata per satuan waktu ditentukan oleh biaya total rata-rata dengan satu waktu tak terbatas. Sebuah periode optimal perawatan preventif (meminimalkan biaya perawatan total) dari sebuah komponen dianggap sebagai kerusakan komponen yang mengikuti sebuah proses gamma. Hasil dari skripsi ini, yaitu nilai ekspektasi dari biaya perawatan total dengan waktu yang terbatas dan periode optimal dari tindakan perawatan preventif. 


\section{B. Perumusan Masalah}

Bagaimana melakukan perawatan sistem yang optimal?

\section{Pembatasan Masalah}

1. Sistem dipandang sebagai suatu komponen.

2. Lama waktu perawatan sistem diabaikan.

\section{Landasan Teori}

\section{A. Sistem Perawatan}

Perawatan (maintenance) merupakan kegiatan untuk menjaga atau memelihara fasilitasfasilitas dan peralatan pabrik, serta mengadakan perbaikan, penyesuaian atau penggantian yang diperlukan untuk mendapatkan suatu kondisi operasi produksi yang memuaskan dan sesuai dengan yang direncanakan. Selain itu, pengertian lain dari perawatan adalah segala tindakan yang dilakukan untuk menjaga kelangsungan fungsional dari sistem produksi dan peralatannya. Di samping itu, ada juga yang mendefinisikan perawatan sebagai suatu konsepsi dari semua aktivitas yang diperlukan untuk menjaga ataupun mempertahankan kualitas peralatan agar tetap dapat berfungsi dengan baik seperti dalam kondisi yang sebelumnya.

Aktivitas perawatan yang sering kali diabaikan oleh pihak perusahaan, sebenarnya merupakan kegiatan yang tidak kalah pentingnya dengan kegiatan lain yang ada di dalam perusahaan. Kegiatan perawatan yang tidak teratur, dapat mengakibatkan mesin dan peralatan mengalami kerusakan, sehingga dapat mempengaruhi kapasitas produksi, serta mengeluarkan biaya-biaya yang mahal untuk melakukan perbaikan.

Perawatan preventif adalah kegiatan perawatan yang dilakukan untuk mencegah timbulnya kerusakan dan menemukan kondisi yang dapat menyebabkan fasilitas atau mesin produksi mengalami kerusakan pada waktu melakukan kegiatan produksi. Sedangkan, perawatan korektif dilakukan untuk memperbaiki dan meningkatkan kondisi fasilitas, sehingga mencapai standar yang dapat diterima. Perawatan korektif termasuk dalam cara perawatan yang direncanakan untuk perbaikan.

\section{B. Proses Renewal}

Misalkan $X_{1}, X_{2}, \ldots$ merupakan barisan variabel acak yang menyatakan waktu-waktu antar kedatangan yang berurutan yang saling independen dan berdistribusi identik. Misalkan

$$
S_{n}=\sum_{i=1}^{n} X_{i} ; n \geq 1 ; S_{0}=0,
$$

dimana $S_{n}$ menyatakan waktu kejadian ke- $n . S_{1}=X_{1}$ adalah waktu renewal pertama, $S_{1}=X_{1}+X_{2}$ adalah waktu renewal pertama ditambah waktu antara renewal pertama dan kedua, dan seterusnya. Banyaknya kejadian sampai waktu $t$ sama dengan nilai $n$ terbesar sedemikian sehingga $S_{n} \leq t$. Maka banyaknya kejadian sampai waktu $t$ diberikan oleh

$$
N(t)=\max \left\{n \geq 0: S_{n} \leq t\right\}
$$

Proses stokastik $N=\{N(t), t \geq 0\}$ yang didefinisikan pada persamaan sebelumnya dinamakan proses renewal. Untuk menentukan distribusi dari $N(t)$, hal pertama yang penting diperhatikan adalah banyaknya renewal pada waktu $t \geq n$ jika dan hanya jika renewal ke- $n$ terjadi sebelum atau pada waktu $t$. Oleh karena itu,

$$
N(t) \geq n \leftrightarrow S_{n} \leq t .
$$




\section{Distribusi Gamma}

Distribusi ini mempunyai laju kerusakan yang menurun dan menaik dengan bertambahnya umur komponen. Distribusi Gamma memiliki dua parameter, yaitu $\alpha$ dan $\beta$. Fungsi Gamma didefinisikan sebagai

$$
\Gamma(\alpha)=\int_{0}^{\infty} x^{\alpha-1} e^{-x} d x, \quad \alpha>0 .
$$

Jika diintegralkan menurut bagian dengan $u=x^{\alpha-1}$ dan $d v=e^{-x} d x$, maka akan diperoleh

$$
\Gamma(\alpha)=(\alpha-1)(\alpha-2)(\alpha-3) \Gamma(\alpha-3) .
$$

Perhatikan jika $\alpha=n$, dengan $n$ bilangan bula positif, maka

$$
\Gamma(n)=(n-1) ! .
$$

Peubah acak kontinu $X$ berdistribusi gamma, dengan parameter $\alpha>0$ dan $\beta>0$, maka fungsi padatnya berbentuk

$$
f(x)=\frac{1}{\beta^{\alpha} \Gamma(\alpha)} x^{\alpha-1} e^{-x / \beta}, \quad x>0,
$$

dimana rataan dan variansi masing-masing, yaitu $\mu=\alpha \beta$ dan $\sigma^{2}=\alpha \beta^{2}$.

\section{Proses Gamma}

Sebuah variabel acak $X$ yang berdistribusi gamma dengan paramter bentuk $a>0$ dan parameter skala $b>0$ memiliki fungsi kepadatan peluang, yaitu

$$
f_{Z}(z)=\frac{(z / b)^{a-1}}{b \Gamma(a)} \exp (-z / b)
$$

dimana $z \geq 0$ dan $\Gamma(a)=\int_{0}^{\infty} z^{a-1} e^{-z} d z$ merupakan fungsi gamma. Notasi $Z \sim G a(a, b)$ mengartikan sebuah variable acak $Z$ mengikuti distribusi gamma dengan parameter bentuk $a$ dan skala $b$. Rataan dan variansi masing-masing adalah $E[Z]=a b$ dan $\operatorname{Var}[Z]=a b^{2}$.

Sebuah proses stokastik kontinu $\{X(t), t \geq 0\}$ dikenal sebagai sebuah proses gamma stasioner dengan parameter bentuk $\alpha>0$ dan parameter skala $\beta>0$, jika memiliki sifat berikut:

1. $X(0)=0$.

2. $\Delta X(t)=X(t+\Delta t)-X(t) \sim G a(\alpha \Delta t, \beta)$ untuk setiap $t \geq 0$ dan $\Delta t=0$.

3. Untuk setiap pilihan dari $n \geq 1$ dan $0 \leq t_{0}<t_{1}<\cdots<t_{n}<\infty$, variabel acak $X\left(t_{0}\right), X\left(t_{1}\right)-X\left(t_{0}\right), \ldots, X\left(t_{n}\right)-X\left(t_{n-1}\right)$ adalah independen.

Jika proses kerusakan $X(t)$ dari sebuah item mencapai tingkat kritis $\zeta$ tertentu, maka item tersebut mengalami kegagalan. Waktu kegagalan $(T)$ didefinisikan sebagai waktu pertama ketika $X(t)$ melebihi $\zeta$. Sehingga, dapat ditulis

$$
T \equiv \inf \{X(t) \geq \zeta\}=\{t \mid X(t) \geq \zeta, X(s)<\zeta \text { untuk } 0 \leq s<t\} .
$$


Saat $X(t)$ merupakan proses gamma stasioner, maka distribusi dari waktu pertama adalah

$$
F_{T}(t)=\operatorname{Pr}(X(t) \geq \zeta)=\frac{\Gamma\left(\frac{\zeta}{b}, a t\right)}{\Gamma(a t)}
$$

dimana $\Gamma(w, z)$ menunjukkan fungsi gamma tidak lengkap, yang didefinisikan

$$
\Gamma(w, z)=\int_{w}^{\infty} u^{z-1} e^{-u} d u .
$$

Distribusi sisa waktu hidup, yaitu waktu yang tersisa untuk tingkat pertama $\zeta$, dari proses gamma, dengan nilai pada waktu $s, X(s)=x_{s}<\zeta$, adalah

$$
F_{T}(t \mid s)=\operatorname{Pr}\left(X(t)-X(s) \geq \zeta-x_{s}\right)=\frac{\Gamma\left(\frac{\zeta-x_{s}}{b}, a(t-s)\right)}{\Gamma(a(t-s))}
$$

dimana $t \geq s$ sama seperti persamaan sebelumnya dengan $\zeta$ dan $t$ yangmasing-masing digantikan oleh $\zeta-x_{s}$ dan $t-s$.

\section{E. Transformasi Laplace}

Jika $f(t)$ merupakan fungsi yang didefinisikan pada interval $[0, \infty)$, maka transformasi Laplace dari $f(t)$ didefinisikan sebagai berikut:

$$
\hat{f}(s)=\int_{0}^{\infty} e^{-s t} f(t) d t
$$

dimana integral tersebut merupakan fungsi dalam parameter $s$, maka notasi lain yang biasa digunakan adalah $F(s)=\mathcal{L}(f(t))$. Agar transformasi Laplace $F(s)$ ada, maka integral tak wajar harus konvergen dan ini dapat dicetak dengan mencari limit:

$$
\int_{0}^{\infty} e^{-s t} f(t) d t=\lim _{b \rightarrow \infty} \int_{0}^{b} e^{-s t} f(t) d t
$$

\section{F. Invers Transformasi Laplace}

Misalkan $f$ merupakan fungsi bernilai riil yang didefinisikan pada interval $[0, \infty)$. Transformasi Laplace dari $f$ didefinisikan sebagai

$$
\hat{f}(s)=\int_{0}^{\infty} e^{-s t} f(t) d t
$$

dimana $s$ variabel kompleks. Apabila diketahui transformasi Laplace $\hat{f}$, maka fungsi asli $f$ dapat ditemukan kembali dengan rumus inversi:

$$
f(t)=\frac{1}{2 \pi i} \int_{a-i \infty}^{a+i \infty} e^{s t} \hat{f}(s) d s=\frac{e^{a t}}{2 \pi} \int_{-\infty}^{\infty} e^{i t u} \hat{f}(a+i u) d u,
$$


dimana $i=\sqrt{-1}$ dan $a$ adalah bilangan riil yang dipilih. Pada umumnya, transformasi Laplace $\hat{f}$ tidak dapat diinversi secara analitik, sehingga diperlukan suatu prosedur untuk menginversi transformasi Laplace secara numerik. Salah satunya dengan menggunakan aturan trapesium.

Integral suatu fungsi $f$ pada interval $[c, d]$ dapat didekati dengan aturan trapesium, dimana $h=\frac{\left(x_{n}-x_{0}\right)}{n}=\frac{(d-c)}{n}$ dan $A_{i}=\frac{h}{2}\left[f\left(x_{i-1}\right)+f\left(x_{i}\right)\right]$, sebagai berikut

$$
\int_{c}^{d} f(x) d x=\sum_{i=1}^{n} A_{i}=h\left[\frac{f(c)+f(d)}{2}+\sum_{k=1}^{n-1} f(c+k h)\right] .
$$

Jika $c=-\infty$ dan $d=\infty$, serta fungsi $f$ terintegralkan pada seluruh garis riil, maka persamaan di atas menjadi:

$$
\int_{-\infty}^{\infty} f(x) d x=h_{1} \sum_{k=-\infty}^{\infty} f\left(k h_{1}\right)
$$

dimana $h_{1}$ merupakan suatu konstanta positif yang kecil.

Dengan $h_{1}=\pi / t, t>0$, dan $a=A / t$ pada waktu yang sama, maka diperoleh

$$
f(t)=\frac{e^{A}}{2 t} \sum_{k=-\infty}^{\infty}(-1)^{k} \hat{f}([A+i \pi k] / t) .
$$

\section{Pembahasan}

\section{A. Biaya Total Perawatan Sistem}

Misalkan pada saat $S_{0}=0$, sebuah komponen baru mulai dioperasikan dan $L$ merupakan panjang jangka waktu untuk melakukan perawatan preventif sejak dioperasikan atau sejak perawatan terakhir jika tidak mengalami kerusakan. Anggap perawatan preventif membuat komponen kembali menjadi baik, seperti baru. Jika komponen rusak sebelum waktu $L$ sejak pertama kali dioperasikan atau setelah melakukan perawatan terakhir, maka dibutuhkan perawatan korektif yang berarti kompenen akan digantikan dengan sebuah komponen baru. Jadi, setelah melakukan kedua jenis perawatan tersebut, maka komponen dalam kondisi yang baik seperti baru

Misalkan $0<S_{1}<S_{2}<\ldots$ merupakan waktu dimana dilakukan perawatan preventif atau perawatan korektif. Karena diasumsikan bahwa kompenen akan berkondisi baik, seperti baru, setelah perawatan komponen dilakukan, maka barisan $\left\{S_{j}, j \geq 1\right\}$ merupakan proses renewal. Ini berarti bahwa waktu antara perawatan yang dilakukan secara berurutan, yaitu

$$
T_{j}=S_{j}-S_{j-1}, \quad j=1,2,3, \ldots,
$$

merupakan variabel acak non-negatif yang berdistribusi independen dan identik. Misalkan $N(t)$ menunjukkan jumlah dari perawatan yang dilakukan selama interval waktu $[0, t]$. Ini berarti

$$
N(t)=\max \left\{j: S_{j} \leq t\right\} .
$$

Misalkan kerusakan komponen dimodelkan sebagai sebuah proses gamma $\{X(t), t \geq 0\}$ dengan rataan $E[X(t)]=\mu t$ dan varians $\operatorname{Var}[X(t)]=\sigma^{2} t$. Fungsi kepadatan probabilitas dari $X(t)$ adalah 


$$
f_{X(t)}(x)=\frac{1}{b^{a} \Gamma(a)} x^{a-1} e^{-\frac{x}{b},} \quad x>0
$$

dimana $a=\frac{\mu^{2}}{\sigma^{2}} t$ dan $b=\frac{\sigma^{2}}{\mu}$. Anggap komponen akan gagal jika kerusakan melibihi level $y$ yang diberikan. Ini berarti bahwa distribusi dari waktu antara perawatan yang dilakukan secara berurutan $T_{j}$ adalah

$$
\operatorname{Pr}\left(T_{j}>s\right)= \begin{cases}\operatorname{Pr}(X(s)<y) & \text { jika } s<L \\ 0 & \text { jika } s \geq L .\end{cases}
$$

Biaya untuk perawatan preventif dan korektif masing-masing dilambangkan dengan $c_{P}$ dan $c_{F}$. Asumsikan bahwa $c_{P}$ dan $c_{F}$ merupakan konstanta non-negatif, yang biasanya $c_{P} \leq c_{F}$. Sebagai akibatnya, biaya total perawatan selama interval waktu $[0, t]$ adalah

$$
K(t)=\sum_{i=1}^{N(t)}\left[c_{P} 1_{\left\{T_{i}=L\right\}}+c_{F} 1_{\left\{T_{i}<L\right\}}\right]
$$

dimana $1_{A}$ menunjukkan fungsi indikator dari himpunan $A$, yakni

$$
1_{A}(x)=\left\{\begin{array}{l}
1, \text { jika } x \in A \\
0, \text { jika } x \notin A
\end{array}\right.
$$

Pada persamaan sebelumnya, dapat diinterpretasikan bahwa selama interval waktu $[0, t]$ biaya yang harus dikeluarkan untuk perawatan komponen adalah $K(t)$. Pada umumnya, nilai uang tergantung pada waktu, sehingga jika seseorang ingin mempersiapkan dana yang diperlukan untuk biaya perawatan komponen pada interval waktu $[0, t]$, maka faktor diskon perlu dimasukkan kedalam perhitungan biaya perawatan komponen. Asumsikan faktor diskon adalah $e^{r t}$, dimana $r \in(0,1)$, sehingga nilai uang pada waktu $t$ setara dengan $e^{-r t}$ nilai uang pada waktu 0. Jadi, jumlah uang yang harus disimpan pada waktu 0 untuk menutup total biaya perawatan selama interval waktu $[0, t]$ dengan suku bunga $r$ adalah

$$
K(t, r)=\sum_{i=1}^{N(t)}\left[c_{P} e^{-r S_{i}} 1_{\left\{T_{i}=L\right\}}+c_{F} e^{-r S_{i}} 1_{\left\{T_{i}<L\right\}}\right] .
$$

Catatan bahwa pada kasus yang tidak terdapat diskon, maka $r=0$. Dalam tulisan ini, periode optimal $L^{*}$ akan ditemukan untuk perawatan preventif yang meminimalkan ekspektasi biaya total perawatan $E[K(t, r)]$ selama dibatasi interval waktu $[0, t]$.

\section{B. Ekspektasi Biaya Total Perawatan Sistem}

Pada bagian ini, akan dibahas nilai ekspektasi dari biaya total perawatan sistem yang dirumuskan sebagai

$$
K(t, r)=\sum_{i=1}^{N(t)}\left[c_{P} e^{-r S_{i}} 1_{\left\{T_{i}=L\right\}}+c_{F} e^{-r S_{i}} 1_{\left\{T_{i}<L\right\}}\right] .
$$


Misalkan $Y_{i}=c_{P} e^{-r S_{i}} 1_{\left\{T_{i}=L\right\}}+c_{F} e^{-r S_{i}} 1_{\left\{T_{i}<L\right\}}$. Karena $N(t) \geq n$ jika dan hanya jika $S_{n} \leq t$, maka

$$
E[K(t, r)]=E\left[\sum_{i=1}^{N(t)} Y_{i}\right]=E\left[\sum_{i=1}^{N(t)} Y_{i} 1_{\{N(t) \geq i\}}\right]=E\left[\sum_{i=1}^{N(t)} Y_{i} 1_{\left\{S_{i} \leq t\right\}}\right] .
$$

Pada umumnya, nilai eskpektasi ini sulit untuk dihitung secara langsung. Salah satu cara untuk mengatasi masalah ini adalah menggunakan transformasi Laplace dari $E[K(t, r)]$ yang dianggap sebagai fungsi dari $t$. Karena $E[K(t, r)]$ adalah non-negatif, maka dapat ditulis sebagai berikut

$$
\int_{0}^{\infty} E[K(t, r)] e^{-\lambda t} d t=\sum_{i=1}^{N(t)} E\left[\int_{0}^{\infty} Y_{i} 1_{\left\{s_{i} \leq t\right\}} e^{-\lambda t} d t\right]=\frac{1}{\lambda} \sum_{i=1}^{N(t)} E\left[Y_{i} e^{-\lambda s_{i}}\right] .
$$

Kemudian,

$$
E\left[Y_{i} e^{-\lambda s_{i}}\right]=E\left[c_{P} e^{-r S_{i}} 1_{\left\{T_{i}=L\right\}} e^{-\lambda S_{i}}+c_{F} e^{-r S_{i}} 1_{\left\{T_{i}<L\right\}} e^{-\lambda s_{i}}\right],
$$

karena $S_{i}=T_{i}+S_{i-1}$, maka

$$
E\left[c_{P} e^{-r S_{i}} 1_{\left\{T_{i}=L\right\}} e^{-\lambda S_{i}}\right]=c_{P} e^{-(\lambda+r) L} \operatorname{Pr}\left(T_{i}=L\right)\left(E\left[e^{-(\lambda+r) T_{1}}\right]\right)^{i-1},
$$

dan

$$
E\left[c_{F} e^{-r S_{i}} 1_{\left\{T_{i}<L\right\}} e^{-\lambda S_{i}}\right]=c_{F} E\left[e^{-(\lambda+r) T_{i}} 1_{\left\{T_{i}<L\right\}}\right]\left(E\left[e^{-(\lambda+r) T_{1}}\right]\right)^{i-1}
$$

Sehingga,

$$
E\left[Y_{i} e^{-\lambda S_{i}}\right]=\left[c_{P} e^{-(\lambda+r) L} \operatorname{Pr}\left(T_{i}=L\right)+c_{F} E\left[e^{-(\lambda+r) T_{i}} 1_{\left\{T_{i}<L\right\}}\right]\right]\left(E\left[e^{-(\lambda+r) T_{1}}\right]\right)^{i-1} .
$$

Jadi,

$$
\int_{0}^{\infty} E[K(t, r)] e^{-\lambda t} d t=\frac{c_{P} e^{-(\lambda+r) L} \operatorname{Pr}\left(T_{1}=L\right)+c_{F} E\left[e^{-(\lambda+r) T_{1}} 1_{\left\{T_{1}<L\right\}}\right]}{\lambda\left(1-E\left[e^{-(\lambda+r) T_{1}}\right]\right)}
$$

Nilai ekspektasi $E[K(t, r)]$ dapat diperoleh dengan menginvers kembali transformasi tersebut secara numerik. Periode optimal untuk perawatan preventif diperoleh dengan meminimalkan nilai ekspektasi dari biaya total perawatan.

\section{Contoh Kasus}

Misalkan kerusakan komponen mengikuti sebuah proses gamma $\{X(t), t \geq 0\}$ dengan rataan $E[X(t)]=5 t(\mu=5)$ dan variansi $\operatorname{Var}[X(t)]=3 t\left(\sigma^{2}=3\right)$, serta jika kerusakan komponen melebihi level $y=15$, maka komponen tersebut akan gagal. Transformasi Laplace dari $E[K(t, r)$ pada persamaan sebelumnya dapat dihitung. Karena $T_{1}=L$ jika dan hanya jika $X(L) \leq y$, maka

$$
\operatorname{Pr}\left(T_{1}=L\right)=\operatorname{Pr}(X(L) \leq y)=\int_{0}^{y} \frac{1}{b^{a_{1} \Gamma\left(a_{1}\right)}} x^{a_{1}-1} e^{-x / b} d x=\int_{0}^{y / b} \frac{1}{\Gamma\left(a_{1}\right)} z^{a_{1}-1} e^{-z} d z,
$$


dimana $a_{1}=25 L / 3$ dan $b=3 / 5$. Integral terakhir merupakan sebuah fungsi gamma tidak lengkap dan dinotasikan dengan $G\left(a_{1}\right)$.

Nilai ekspektasi $E\left[e^{-(\lambda+r) T_{1}}\right]$ diberikan oleh

$$
E\left[e^{-(\lambda+r) T_{1}}\right]=E\left[e^{-(\lambda+r) T_{1}} 1_{\left\{T_{1}<L\right\}}\right]+E\left[e^{-(\lambda+r) T_{1}} 1_{\left\{T_{1}=L\right\}}\right]+E\left[e^{-(\lambda+r) T_{1}} 1_{\left\{T_{1}>L\right\}}\right] .
$$

Karena nilai $T_{1}$ tidak mungkin lebih dari nilai $L$, maka bagian ketiga dari persamaan di atas bernilai 0 . Bagian kedua dari persamaan tersebut adalah

$$
E\left[e^{-(\lambda+r) T_{1}} 1_{\left\{T_{1}=L\right\}}\right]=e^{-(\lambda+r) L} \operatorname{Pr}\left(T_{1}=L\right) .
$$

Bagian pertama dari persamaan tersebut adalah

$$
E\left[e^{-(\lambda+r) T_{1}} 1_{\left\{T_{1}<L\right\}}\right]=\int_{0}^{L^{-}} e^{-(\lambda+r) z} d F(z),
$$

dimana $F(z)=\operatorname{Pr}\left(T_{1} \leq z\right)$. Dengan menggunakan aturan trapesium, maka akan didapat

$$
\int_{0}^{L^{-}} e^{-(\lambda+r) z} d F(z)=\sum_{j=1}^{n} e^{-(\lambda+r)\left(j-\frac{1}{2}\right) \frac{L}{n}}\left[F\left(\frac{j L}{n}\right)-F\left((j-1) \frac{L}{n}\right)\right] .
$$

Perhatikan bahwa

$$
F\left(\frac{j L}{n}\right)=1-\operatorname{Pr}(X(j L / n) \leq y)=1-\int_{0}^{y / b} \frac{1}{\Gamma\left(a_{2}\right)} z^{a_{2}-1} e^{-z} d z=1-G\left(a_{2}\right) .
$$

dan dengan menggunakan cara yang sama, maka didapat

$$
F\left((j-1) \frac{L}{n}\right)=1-\int_{0}^{y / b} \frac{1}{\Gamma\left(a_{3}\right)} z^{a_{3}-1} e^{-z} d z=1-G\left(a_{3}\right),
$$

dimana $a_{2}=25 j L / 3, a_{3}=25(j-1) L / 3$, dan $\mathrm{b}=3 / 5$. Dengan demikian,

$$
E\left[e^{-(\lambda+r) T_{1}} 1_{\left\{T_{1}<L\right\}}\right]=\sum_{j=1}^{n} e^{-(\lambda+r)\left(j-\frac{1}{2}\right) \frac{L}{n}}\left[G\left(a_{3}\right)-G\left(a_{2}\right)\right] .
$$

Jadi,

$$
\int_{0}^{\infty} E[K(t, r)] e^{-\lambda t} d t=\frac{c_{P} e^{-(\lambda+r) L} G\left(a_{1}\right)+c_{F} \sum_{j=1}^{n} e^{-(\lambda+r)\left(j-\frac{1}{2}\right) \frac{L}{n}}\left[G\left(a_{3}\right)-G\left(a_{2}\right)\right]}{\lambda\left(1-\sum_{j=1}^{n} e^{-(\lambda+r)\left(j-\frac{1}{2}\right) \frac{L}{n}}\left[G\left(a_{3}\right)-G\left(a_{2}\right)\right]-e^{-(\lambda+r) L} G\left(a_{1}\right)\right)} .
$$

Dengan menggunakan sebuah invers algoritma untuk menginversikan transformasi Laplace dari fungsi di atas, maka didapat grafik dari fungsi $E[K(t, r)]$ untuk beberapa nilai $L$, dapat dilihat pada Gambar 1. Di dalam gambar tersebut, telah ditentukan nilai untuk biaya perawatan preventif $c_{P}=$ 3 , biaya perawatan korektif $c_{F}=5$, suku bunga dari faktor diskon $r=0,04, n=50, M=100$, 
danpanjang $L$ dimulai dari 0,5 sampai 10 dengan nilai $s=0,1$. Di dalam gambar tersebut, didapat nilai periode optimal $L^{*}$ yang meminimalkan nilai ekspektasi dari biaya total perawatan sistem dengan interval waktu $[0,50]$, yaitu sekitar 2,1. Ini mengartikan bahwa cara melakukan perawatan sistem yang optimal pada ilustrasi tersebut, yaitu dengan melakukan kegiatan perawatan preventif secara berkala setiap periode optimal $L^{*}=2,1$ dalam interval waktu $[0,50]$. Karena pada saat panjang periode optimal $L^{*}=2,1$ dapat meminimalkan nilai ekspektasi yang dari biaya total perawatan komponen tersebut. Jadi, dapat disimpulkan cara untuk melakukan perawatan yang optimal, yaitu dengan menentukan nilai periode optimal yang tepat untuk dapat meminimalkan nilai ekpektasi dari biaya total perawatan komponen tersebut.

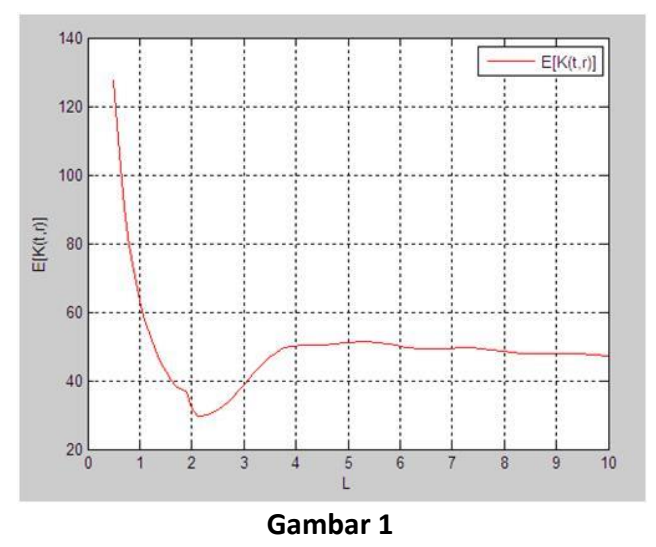

\section{Penutup}

\section{A. Kesimpulan} berikut:

Berdasarkan hasil pembahasan di atas, maka dapat diambil beberapa kesimpulan sebagai

1. Ekspektasi biaya total perawatan sistem selama interval waktu $[0, t]$ dan suku bunga $r \in$ $(0,1)$ dengan sebuah periode optimal perawatan preventif dari sebuah komponen dianggap sebagai kerusakan komponen dianggap sebagai sebuah proses gamma, yaitu:

$$
\int_{0}^{\infty} E[K(t, r)] e^{-\lambda t} d t=\frac{c_{P} e^{-(\lambda+r) L} \operatorname{Pr}\left(T_{1}=L\right)+c_{F} E\left[e^{-(\lambda+r) T_{1}} 1_{\left\{T_{1}<L\right\}}\right]}{\lambda\left(1-E\left[e^{-(\lambda+r) T_{1}}\right]\right)} .
$$

2. Perawatan sistem yang optimal pada ilustrasi pada pembahasan, yaitu dengan kegiatan perawatan preventif secara berkala setiap periode optimal $L^{*}=2,1$ dalam interval waktu $[0,50]$ karena dapat meminimalkan nilai ekspektasi dari biaya total perawatan komponen tersebut. Jadi, dapat disimpulkan bahwa cara untuk melakukan perawatan yang optimal, yaitu dengan menentukan nilai periode optimal yang tepat untuk dapat meminimalkan nilai ekpektasi dari biaya total perawatan komponen tersebut.

\section{B. Saran}

1. Sistem yang dibahas adalah sistem yang dianggap sebagai suatu komponen. Disarankan kepada peneliti selanjutnya untuk mencari bagaimana formula untuk sistem yang terdiri dari $n$ komponen.

2. Kerusakan komponen mengikuti sebuah proses gamma. Disarankan kepada peneliti selanjutnya untuk menggunakan proses lain selain proses gamma, misalkan distribusi Weibull. 


\section{Daftar Pustaka}

C. Wolstenholme, Linda. 1999. "Reliability Modelling: A Statistical Approach". United States of America: Chapman \& Hall/CRC.

Cheng, Tianjin. 2011. "Stochastic Renewal Process Models for Maintenance Cost Analysis". Canada : University of Waterloo.

Suyono. 2003. "Renewal Processes and Repairable Systems". Netherlands : Delft University of Techonogy.

Suyono dan Weide, J.A.M. van der. "Optimal Age Replacement with Discounted Cost". Netherlands : Delft University of Techonogy.

Yuan, Xianxun. 2007. "Stochastic Modeling of Deterioration in Nuclear Power Plant Components". Canada : University of Waterloo.

Zulfikar. 2012. "Availabilitas Sistem dengan Waktu Perbaikan Singkat". Jakarta : Universitas Negeri Jakarta.

http://library.binus.ac.id/eColls/eThesisdoc/Bab2/2008-2-00506-TI\\%20Bab1\%202.pdf\}.(diakses: 21 Juni 2015). 